\title{
Motivation to Travel as A Result Of Work Stress and Life Routine: The Case of Egyptian Vacationers
}

\author{
Dalia F. Amara \\ Lecturer - Hotels and Tourism Department \\ Arab Academy for Science, Technology and Maritime Transport, Egypt
}

\begin{abstract}
Nowadays, most Egyptian vacationers are encouraged more and more to go on holiday. It has become a "normal" decision in their lives. This study examined the role of stress and routines as a motivator encouraging people to take decisions to travel for a holiday. It attempted to find what that means for the way they decide on their vacation. If stress exists, what factors influence holiday decisionmaking, and destination selection. This study investigates the potential of travel experiences as a stress and routine reliever. The study was based on an exploratory qualitative approach for data collection including 46 random sample of Egyptian managers, workers and households. The results revealed the benefits of tourism trips influencing vacationers' life satisfaction. Stress relief seemed to be one of the main implicit factors that tourists consider when making a decision to travel in general or to choose a particular destination. Furthermore, tourism marketers may use these results in their provision and communication of services to Egyptian tourist market.
\end{abstract}

Keywords: vacation, stress, routine, travel, life satisfaction. Qualitative, research.

\section{Introduction}

Tourism has been widely regarded as beneficial for mental and physical health
(Richards, 1999). A number of tourism studies suggest that overall life satisfaction is influenced by how individuals evaluate various life domains (such as leisure, work, health, or family). A series of studies have been conducted to examine leisure travel as a life event on individuals' life satisfaction, and the results have revealed that satisfaction with a leisure trip can influence positively life satisfaction after a trip (Sirgy et al., 2011). Oh et al., (2007) have identified four realms of tourism experiences, including entertainment, esthetics, escapism, and education experiences. Tourism experiences have been found to be composed of hedonism, novelty, local culture, refreshment, meaningfulness, involvement, and knowledge dimensions. The motive of many vacation makers is in a response to psychological depletion and is an opportunity to allow the tourist to replenish and restore, if the traveler finds what they want they will come back enriched, regenerated \& recharged. More than almost any other industry, travel and hospitality have the ability to create long lasting memories and enjoyment. Emotions are often charged during travel, with anticipation, excitement as, the essence of a vacation was the individual having a break from their typical routine and within most theories of motivation the concept of a stable equilibrium is either stated or implied. Equilibrium would be resorted at the 
conclusion of the vacation after the needs of the tourist had been meet in order to relieve the tension in the motivational system. It was suggested that by going away on vacation an individual is able to escape the suppressing feeling of isolation in everyday life and obtain social interaction by getting away from the norms of everyday living. It is interesting to

\section{Research Aim}

As stress negatively affects the performance of employees at any workplace. The study aims to investigate the potential of travel experiences as a stress and routine reliever. It analyses leisure travel, considered among the successful motivational factors provided to employees resulting in job satisfaction.

\section{Holiday decision making}

In the past two decades the vacation decision making has become an important issue in tourism research. Consumers are influenced in their decision-making processes by many internal and external motivators when they choose products. The experience of purchasing a holiday, is likely to take much more time and involve more careful consideration and selection, unlike the purchasing of an everyday food item, as the purchase of a holiday usually involves a high proportion of income. The decision to purchase a tourism product is the outcome of a complex process. This is the result of a number of factors, which relate to the consumer and to the external influences that act upon them. However, it is also true that the diverse and interdependent characteristics of many tourism products make the purchase decision in tourism a complex phenomenon in its own right. A range of decisions is to be done when choosing a holiday; this may include; which destination to be visited? which mode of travel? which type of accommodation? how long will the holiday note that the holiday decision making is predominantly dynamic in nature. It is not marked by fixed sequential stages or an abrupt end once decisions are taken. Decisions are related to several attributes (landscape, climate, amenities etc.) (Schiffman, L. et al., 2007).

be? at which time of the year will the holiday be taken? is it a package holiday or independent travel? and if package holiday, which tour operator? etc. (Horner, S. \& Swarbrooke J. ,2016).

\section{Tourism as a Stress Reliever:}

Tourism as a service poses many issues in terms of consumer behavior. While there are many tangible items associated with it, the tourism product is largely a series of experiences. These experiences usually consist of intangible benefits, such as a sense of wellbeing, mental and physical recuperation, development of personal interests such as culture, or revived relationships (Middleton, 2001).Tourism studies provide a foundation for understanding the role of leisure travel in tourists' satisfaction with life overall (sense of well-being), demonstrating that satisfaction with travel leisure is determined by the extent to which the trip is perceived to provide the tourist with a certain degree of freedom from control and work, that the trip is perceived to be involving and arousing, that the leisure activities involve a certain sense of mastery, and finally that the leisure travel allows a certain degree of spontaneity (Unger \& Kernan, 1983). Though the average person may not experience the kind of mega stress of an elected leader, all people have their own home-grown version of job - related stress. All may face the burden of meeting tight deadlines, making crucial decisions, or managing the complexities of household 
demands. According to Swanson et al. (2008) stress at work may occur because of different factors including individual, socio-economic and family matters. Taking a leisure trip provides opportunities for relaxation, detachment from work, mastery experience, and personal control (Chen, C. et al., 2014). Motives behind international travel involves push and pull motives which are discussed in a wide range of travel motivation studies (Yiamjanya, S., \& Wongleedee, K., 2014). Some common push factors in traveling found in many studies include escape from routine everyday life, relaxation, exploration, social interaction, relationship enhancement and prestige (Jensen, J.M.,2011). Consequently, stress relief seemed to be one of the main implicit factors that tourists consider when making a decision to travel in general or to choose a particular destination.

\section{Research Methodology}

\subsection{Qualitative approach}

The study was based on an exploratory qualitative approach. The researcher chooses the qualitative approach as interviews are not limited to particular questions and can be redirected or guided by her in real time and consequently, issues and subjects covered can be evaluated in depth and in detail (Rahman, S.,2017). Qualitative research design (interactive approach) has a flexible structure as the design can be constructed and reconstructed to a greater extent (Maxwell, 2012). Thus, the thorough and appropriate analyses of an issue can be produced by utilizing qualitative research methods, and therefore the participants have sufficient freedom to determine what is consistent for them (Flick, 2014). As a result, the complex issues can be understood easily. The qualitative research admits the researchers to discover the participants' inner experience, and to figure out how meanings are shaped through and in culture (Corbin \& Strauss, 2008). Chalhoub-Deville \& Deville (2008), too, argued that qualitative approaches are employed to achieve deeper insights into issues related to designing, administering, and interpreting language assessment. The data in qualitative research depends on human experience hence, complexity and arguments about the research's subjects is usually missed by many positivistic inquiries. Moreover, since this type requires smaller scales, low cost is therefore another advantage.

\subsection{Sampling}

The participants of the study have been selected by the researcher using purposive sampling method. This purposive sampling technique is also referred to as a judgmental or expert sample. The main objective of a purposive sample is to produce a sample that can be logically assumed to be representative of the population. This is often accomplished by applying expert knowledge of the population to select in a nonrandom manner a sample of elements that represents a crosssection of the population. In purposive sampling, each element in the population has a known nonzero chance of being selected through the use of a random selection procedure. Rather, subjective methods are used to decide which elements should be included in the sample (Paul J.Lavrakas, 2008).

Forty-six in-depth interviews were conducted among a nonrandom sample of Egyptian managers, workers and households. Each interview lasted approximately 25 minutes. All the participants were participating on their own will and no participant has been forced for any sort of contribution. The sample size is appropriate in relation to the type of sampling technique employed (Patton ,2002). 
Qualitative samples must be large enough to assure that most or all of the perceptions that might be important are uncovered, but at the same time if the sample is too large data becomes repetitive and, eventually, superfluous. It is also, very labor intensive, analyzing a large sample can be time consuming and often simply impractical (Crouch \& McKenzie, 2006). If a researcher remains faithful to the principles of qualitative research, sample size in the majority of qualitative studies should generally follow the concept of saturation. Sampling continues until the researcher senses reaching saturation of knowledge. Saturation is a problematic term (Mason M. ,2010). For example, by (say) the fifteenth interview, the researcher recognizes patterns in the interviewees' experiences. More interviews confirm what the researcher has already sensed. How saturation of knowledge is reached or passed during sampling is uncertain. According to Mason M., (2010), it is more likely using qualitative interviews will stop sampling when the number of samples is a multiple of ten rather than when saturation has occurred. Guest et al. (2006) found that 12 interviews of a homogenous group is all that is needed to reach saturation. Conceptually, saturation may be the desired end point of data collection. Operationally, the decision to stop interviewing is a function of a combination of all or some of the other factors such as: interview structure and content, heterogeneity of the group (Guest et al., 2006), the number of interviews done already, the complexity of the interviews, the researcher's experience, fatigue, the number of researchers in the research team (Bernard \& Ryan, 2010). Ritchie et al. (2003) added the budget and resources available. Lee, Woo and Mackenzie (2002) suggested as well that studies that use multiple (very in-depth) interviews with the same participant (e.g. longitudinal or panel studies) require fewer participants, which is the case of this study.

The survey was carried out in Alexandria, second biggest city in Egypt, at two selected locations which are; City center shopping center, which is the biggest shopping center in Alexandria and neighbor governorates and Alexandria Sporting club, one of the oldest clubs in Egypt and Africa, founded in 1890. Personal interviews conducted in shopping malls are referred to as mall intercept interviews and are low cost. Both places where selected targeting a special population segment, who can afford to travel and would decide to go on vacation as a result of work stress or life routine.

\subsection{The laddering technique}

Market researchers have adapted the laddering method for use in consumer and organizational research. However, in addition to adapting the research method itself, early marketing practitioners conceived and refined a model for describing the linkages between customers' values and their overall purchasing behavior: the Means End Chain theory. This theory provides both a framework for capturing qualitative laddering research data in the consumer space and a model for assessing consumer values and behaviors. "Laddering technique was used. The laddering is an interviewing technique that maps out meansend chains.

The real power of the means -end chain model is that it emphasizes why and how products are important in an individual's life, going beyond a reported description of functional attributes. Customarily, laddering interviews are conducted face to face (Reynolds \& Olson ,2001). The technique involves a series of questions that are related hierarchically. In other words, one question generates a 
response, which is followed up by the interviewer with a further probe (why...?), which in turn generates another response from the participant, which in turn is followed by an additional probe (why . . .?), until the participant cannot seem to respond anymore. The researcher began with a general question ("Did you go on a vacation trip to some tourist destination in the past six months or so?"). If the interviewee responded affirmatively, then all subsequent questions focused on that trip, including purpose of the trip? how often did he or she go for vacation? What motivate them to travel, and more specifically go on vacation. Of course, if the interviewee responded negatively, then that person was dismissed. The interviewer then asked, "How did this trip affect your quality of life? Specifically did your trip affect your work life, and /or social life? "How far work stress and routine can be a motive to take the decision to travel? Interviewee was also asked to define the need to escape from everyday life routine.

Interviews questions were covering as well the vacation decision making process, responses were focusing on travel details including various travel aspects such as transportation, destination choice, and travel restrictions like visa procedure.

\section{Results and Discussion}

The demographics of the selected participants were of varying ages (21 to 52 years old) and of both gender (32 men and 14 women). Responses of the selected participants determining their job motivation sources, indicated that monetary compensation or rewards is the most influential factor that motivates them at work. However, others noted that a challenging work environment, qualities of leadership, paid holidays, incentive trips as well as learning development opportunities are also motivating factors at their workplace. Investigating the selected participants regarding the factors that affect their level of job satisfaction, interviews' participants stated that benefits are the most important factor that affects their job satisfaction, including; job insurance (medical insurance), salary leverage, overtime payment, and promotion opportunities are also very significant factors.

Participants' responses stressed their stress feelings as a result of work overload in other words number of employees versus work load, long working hours, unhealthy work atmosphere and generally from life routines. Results concerning actions taken when facing stress from work conditions include taking a break and/or reducing their working hours to reduce stress level. The majority of the participants agreed that leisure travel is the most satisfying action helping them to recover from work stress.

Interviewee responses concerning the definition of the escape from everyday life routine through a travel experience, include; having fun mainly with friends, doing something exciting, reducing stress, relaxing, learning new things, meeting new people, and /or discovering and experiencing new destination(s).

The results generated from the in-depth interviews, revealed the ranking of the first top five attributes that influenced vacationers, when stressed or when in need to escape from work and or life routine, which are beaches, climate/ weather, landscape, exotic scenery of the place and finally food, as food still is a key factor in deriving tourists' general satisfaction of a destination (Ardabili, F. S. et al. ,2011), as food become part of their travel memories. And thus, can enhance the holiday's attractiveness, while representing noveltyseeking behavior. 
Results indicate that a domestic vacation in most cases required a less extensive decisionmaking process compared to a vacation abroad. Respondents' stressed the fact that living in big cities and capitals puts pressures on them to truly escape and feel like 'traveling to a local country side 'that is not far enough away is paramount, to get away from work/life routine and stress. Factors related to both the type of vacation and type of vacation play an important role. As well, ranging from taking a weekend to spending longer trips can be a remedy, helping people to recover from work stress.

The benefits of vacations extend to family relationships. Results concluded that family vacations contribute positively to family bonding, communication and solidarity. As vacations promote what is called the "crescive bond" or a "shared experience" by fostering gradual spontaneous growing and enduring connections. Shared family memories and time spent together isolated from ordinary everyday activities (school, work, and so on) help to promote these positive ties. Though family vacations can have their own share of stress, the benefits outweigh the risks, even families that are not particularly close, according to Lehto, X. Y. et al., 2009).

The overarching finding was that taking time off from work makes people happier, healthier in other words stress-free and therefore more productive when they return to work. This was expressed by managers as happiness raises productivity and sales.

But one the other hand, some of the findings were directed towards the fact that, "not every vacation is equal". As poorly planned and stressful vacations eliminate the positive benefit of time away. The less the stress, the more likely you will experience a positive benefit from your vacation. As positive and well managed vacations have a significant effect upon workers 'levels of energy and stress. According to Harvard Business review study (2014), 94\% had as much or more energy after coming back after a good trip. In fact, on low-stress trips, 55\% returned to work with even higher levels of energy than before the trip (Shawm A., 2014).

Results indicated that traveling changed the sense of well-being of those participating in it. A holiday decision -taking revealed a higher sense of well-being prior and post travel trips. Respondents experienced a higher amount of pleasant feelings after their holidays; these holidays provide satisfaction which generates positive moods to enhance an individual's sense of well-being. In this respect, this fits with the view that people travel because they have been motivated by some felt needs, which are psychological in nature and can only be satisfied by tourism activity. Therefore, the motivations of the holiday makers represent the salient goals to be achieved at the end of their vacations. If the holiday maker feels that most of his or her tourism expectations (motivations) have been met or satisfied, and that their vacation has the potential to break into the stress cycle. he or she will most likely appraise the holiday as stress reliever.

\section{Conclusion}

Stress is a phenomenon that prove to be costly for organizations as it may become the cause of increased employee turnover (Villanueva \& Djurkovic, 2009). As the primary drivers for travelling are needs to escape from daily routine, workplace, but also social needs such as meeting other people, experiencing something unique or unusual (Simkova, E., Holzner, J., 2014). A person can emerge from a successful vacation feeling ready to take on the world again. Holiday taking as a form of leisure activity and experience can help 
individuals to escape from everyday life routine and enhance their sense of happiness. This is based upon the premise that going on a vacation represents a distinct break from normal events and the experience has had a positive effect to change the respondents' normal levels of subjective well-being.

\section{References}

1. Ardabili, F. S. et al. (2011). "The Role of Food and Culinary Condition in Tourism Industry", MiddleEast Journal of Scientific Research, 9(6), pp. 826833.

2. Bernard, H. R., \& Ryan, G. W. (2010). Analyzing qualitative data: Systematic approaches. Los Angeles, CA: Sage.

3. Chalhoub-Deville, M., \& Deville, C. (2008). Utilizing psychometric methods in assessment. In E. Shohamy, \& N. H. Hornberger (Eds.), Encyclopedia of language and education (2nd ed., Vol. 7, pp. 211-224). New York, NY: Springer Science + Business Media LLC.

4. Chun-Chu Chen, James F.Petrick, \& Moji Shahvali (2014). Tourism Experiences as a Stress Reliever: Examining the Effects of Tourism Recovery Experiences on Life Satisfaction, Journal of Travel Research ,1-11.

5. Corbin, J., \& Strauss, A. (2008). Basics of qualitative research. London: SAGE Publications Ltd.

6. Crouch \& McKenzie (2006). The logic of small samples in interview based qualitative research. Social Science Information, 45(4), 483-499.

7. Flick, U. (2014). An introduction to qualitative research (5th ed.). London: Sage Publications Ltd.

8. Guest, Greg; Bunce, Arwen \& Johnson, Laura (2006).

9. "How many interviews are enough? An experiment with data saturation and variability". Field Methods, 18(1), 59-82.

10. Horner,S. \& Swarbrooke J. (2016). Consumer Behaviour in Tourism.3 edn. Routledge. New York

11. Jensen, J.M. (2011). "The Relationships between Socio- Demographic Variables, Travel Motivations and Subsequent Choice of Vacation", International

12. Conference on Economics, Business and Management, IPEDR, vol.22, Singapore: IACSIT Press.

13. Lee, Diane T.F.; Woo, Jean \& Mackenzie, Ann E. (2002). The cultural context of adjusting to nursing home life: Chinese elders' perspectives. The Gerontologist, 42(5), 667-675.

14. Lehto, X. Y., Choi, S., Lin, Y., \& MacDermid, S.M. (2009). Vacation and family functioning. Annals of Tourism Research, 36, 459-479.

15. Mason, M. (2010). Sample Size and Saturation in $\mathrm{PhD}$ studies using Qualitative Interviews. Forum: Qualitative Social Research. 11(3): Art.8 http://www.qualitativeresearch.net/index.php/fqs/article/view/1428/3027 [Accessed 02 January 2018]

16. Maxwell, J. A. (2012). Qualitative research design: An interactive approach. London: Sage.

17. Middleton, V.T.C. (2001). Marketing in Travel and Tourism, (3nd ed) Oxford: ButterworthHeinemann.

18. Oh, Haemoon, Ann Marie Fiore, \& Miyoung Jeoung (2007). "Measuring Experience Economy Concepts:

19. Tourism Applications." Journal of Travel Research, 46 (2): 119-32.

20. Patton, M. (2002). Qualitative research and evaluation methods. 3rd Sage Publications; Thousand Oaks, CA

21. Paul J.Lavrakas (2008). Encyclopedia of Survey Research Methods. SAGE Publications, https://uk.sagepub.com/en-gb/afr/encyclopedia-ofn survey-research- methods/book227714 [ Accessed 02 January 2018]

22. Rahman, S. (2017). The Advantages and Disadvantages of Using Qualitative and Quantitative Approaches and Methods in Language "Testing and Assessment" Research: A Literature Review. Journal of Education and Learning; 6 (1). Canadian Center of Science and Education. URL: http://dx.doi.org/10.5539/jel.v6n1p102

23. Reynolds, T.J. \& Olson, J.C. (2001). Understanding Consumer Decision Making: the means-end approach to marketing, Routledge, 25-61

24. Richards, Greg (1999). "Vacations and the Quality of Life: Patterns and Structures." Journal of Business Research, 44 (3): 189-98.

25. Ritchie, Jane; Lewis, Jane \& Elam, Gillian (2003). Designing and selecting samples. In Jane Ritchie \& Jane Lewis (Eds.), Qualitative research practice. A guide for social science students and researchers (pp.77-108) Thousand Oaks, CA: Sage.

26. Schiffman, L., Kanuk, L. and Hansen, H. (2007). Consumer Decision-making. In: Consumer Behaviour: A European Outlook. London: Pearson. 74-75 
27. Shawm Achor, (2014). When a vacation Reduces Stress - And when it does not, Harvard Business Review study HBR.

28. Simkova,E., \& Holzner,J., (2014). Motivation of Tourism Participants. El Sevier, 159: 660-664.

29. Sirgy, M. Joseph, P. Stephanes Kruger, Dong-Jin Lee, and Grace B. Yu. (2011). "How Does a Travel Trip Affect Tourists' Life Satisfaction?” Journal of Travel Research, 50 (3): 261-75.

30. Swanson, V., Power, K. G., \&Simpson, R. J. (2008). "Occupational stress and family life: A comparison of male and female doctors", Journal of Occupational and Organizational Psychology. 237 60.

31. Unger, L. S., \& J. B. Kernan (1983). "On the Meaning of Leisure: An Investigation and Some Determinants of the Subjective Leisure Experience." Journal of Consumer Research, 9: 381-92.

32. Villanueva, D., \& Djurkovic, N. (2009). "Occupational stress and intention to leave among employees in small and medium enterprises", International Journal of Stress Management. 124137

33. Yiamjanya, S., \& Wongleedee, K. (2014). International Tourists' Travel Motivation by PushPull Factors and the Decision Making for Selecting Thailand as Destination Choice. International Science Index, Humanities and Social Sciences 8 (5), waset.org/Publication/9998199 